\title{
Predicting attendance at child and adolescent clinics
}

\author{
Rob Potter and Ahmed Darwish
}

\begin{abstract}
Non-attendance rates are high in child psychiatiry clinics. This potential waste of resources is coming under increasing scrutiny within the NHS. This study shows that therapists themselves are good at predicting who will aftend and who will not. The family's previous attendance rate is the most rellable predictor. Why then is not more use made of this information when organising clinics? Ways are suggested how attendance rates might be improved.
\end{abstract}

A significant proportion of patients in child and adolescent psychiatry clinics fail to attend appointments. This is true of new and follow-up appointments and might lead to inefficient use of the therapist's time and resources. In the present climate in the NHS the numbers seen, whether by a particular service or clinic, or by a particular team or individual, are the subject of ever closer scrutiny. There is pressure to reduce nonattendance rates, although the reasons underlying these may not be under the control of the therapist. The literature suggests areas which might help decide whether a family is likely to continue in therapy. The results of this are in part contradictory, and the overall impression is of the number and diversity of the different factors which might determine whether an appointment is kept or not.

Whether looking at socioeconomic (Gould et al, 1985; Kazdin, 1990; Beer, 1992; Kazdin \& Mazurick, 1994), or demographic factors, at family or parental factors (Cottrell et al, 1988; Armbruster \& Schwab-Stone, 1994; Kazdin \& Mazurick, 1994), or at the pattern of presenting symptoms (Gould et al, 1985; Kazdin, 1990: Beer, 1992; Kazdin \& Mazurick, 1994) the results are conflicting and no clear conclusions can be drawn. The two most frequently given reasons for dropping out of treatment are that the child does not want to return, and that treatment is no longer required (Gould et al, 1985).

It is also important to consider what the family might criticise in the psychiatric service. There are issues around convenience, cost, image, stigmatisation which might prevent them from attending. Once they have been seen, there might still be differing expectations of treatment, perhaps in terms of duration, focus or expected outcome (Pekarik, 1985). Beer (1992) also found that staff inexperience, shorter initial interview duration and type of treatment offered, all had implications for continued attendance.

This study looks at how well therapists can predict the return of a client, and which reasons tend to be most reliable in helping the therapist to make this decision.

\section{The study}

This study was undertaken in one of the four consultant led Child and Adolescent Psychiatry teams based at the Brynffynon Clinic in MidGlamorgan. Mid-Glamorgan is an area of severe deprivation (Mortimer, 1991). The therapists in this team completed the data form for each separate case seen throughout a three month period from October 1993 to January 1994. They were requested to give patient identification details; to state whether they thought the family would attend the next appointment offered; and to state the main reason or reasons they had decided this.

\section{Findings}

In this period 80 families were seen. Of these 31 (39\%) attended the next appointment offered; 49 (61\%) did not. Seventy-five per cent of the predictions about attendance were correct. The therapists predicted that $35(44 \%)$ of the cases would attend; of which $66 \%$ were correct predictions. It was predicted that $45(56 \%)$ of the cases would not attend; of which $82 \%$ were correct predictions.

The main reasons for making these predictions were concerned with the previous record of attendance in 47 of the 80 cases. The reason was given as previous poor attendance for 30 families (25 correct predictions) and previous good attendance for 17 families (12 correct predictions). Other reasons given included 'clinical assessment of the case' (11 predictions of which 8 were correct): impression of the family's motivation to attend ( 7 predictions of which 5 were correct); the family's generic social worker had undertaken to ensure that the 
family would attend (7 predictions of which 6 were correct); and other or no reason given in 9 cases ( 6 correct).

The therapists' assessment of previous attendance was a very good predictor of subsequent attendance $\left(\chi^{2}=12.30 \quad P=<0.001\right)$. The other reason given gave some indication of whether the family was likely to attend, but the numbers involved were small.

\section{Comment}

The findings from this study might seem selfevident: that those families with a poor attendance record are unlikely to keep subsequent appointments. However, what the study does show is that clinicians, without going into meticulous detail about the patient's background, socioeconomic status, diagnosis etc. are often able to predict accurately who is likely to attend clinic and who is not.

Why then, if we think that we know this information already, do we not use it? Asking the family to state specifically if they want a further appointment and when they would be able to attend; perhaps telephone prompting (Brockless, 1990): or even sending a questionnaire (Mathai \& Markantonakis, 1990) might be effective ways to ensure better attendance. This might be particularly relevant with those families least likely to attend. At least it could mean that the therapist should know whether the family is going to attend or not in time to allocate the appointment to someone else.

\section{References}

ARMBRUSTER, P. \& SCHWAB-STONE, M. (1994) Sociodemographic characteristics of drop-outs from a child guidance clinic. Hospttal and Communtty Psychiatry. 46, 804-808.

BEER, R. (1992) A pre-school child psychiatric service: predictors of post assessment default. Child: Care. Health and Development, 18, 1-13.

Brockuess, J. (1990) The effects of telephone contact/ prompting on subsequent attendance at initial appointments at a hospital department of child and adolescent psychiatry. Newsletter of the Association of Child Psychology and Psychiatry, 12, 5-8.

COTTREL, D., HmL, P., WALK, D., et al (1988) Factors influencing non-attendance at child psychiatry outpatient clinics. Brttish Joumal of Psychiatry. 162. 210-201.

GOULD, M.. SHAFFER, D. \& KAPLAN, D. (1985) The characteristics of drop-outs from a child psychlatry clinic. Joumal of the American Academy of Child and Adolescent Psychiatry. 24, 316-328.

KAZDIN, A. E. (1990) Premature termination of treatment among children referred for antisocial behaviour. Journal of Child Psychology and Psychiatry, 31, 415-425.

- \& Mnzurick. J. (1994) Dropping out of child psychotherapy: distinguishing early and late drop-outs over the course of treatment. Journal of Consulting and Clinical Psychology, 62, 1069-1074.

MATHN, J. \& MARKANTONAKIS, A. (1990) Improving initial attendance to a child and family psychiatric clinic. Psychiatric Bulletin of the Royal College of Psychiatry. 14. 151-152.

MORTIMER, P. (1991) Economic and Soctal Condittons in MidGlamorgan. Cardiff: Economic Policy Research Unit.

PEKarIK, G. (1985) Coping with drop-outs. Professional Psychology Research and Practice, 16, 114-123.

*Rob Potter, Senior Registrar; and Ahmed Darwich, Consultant, Brynffynon Child and Family Clinic, Merthyr Rd., Pontypridd, MidGlam. CF37 4DD

*Correspondence 